\title{
La grippe, maladie épidémique ubiquitaire défiant toutes prévisions
}

\section{P. Saliou}

Reçu le 21 février 2011 ; accepté le $1^{\text {er }}$ mars 2011

(C) Société de pathologie exotique et Springer-Verlag France 2011

Jusqu'à la fin du siècle dernier, un éditorial sur la grippe aurait pu paraître incongru dans le Bulletin de la Société de pathologie exotique tant cette maladie était sous-estimée, car tout simplement, elle n'était pas diagnostiquée sous les tropiques.

L'épidémiologie de la grippe saisonnière est bien connue. La maladie sévit chaque année en hiver dans les zones tempérées de chaque hémisphère, donnant lieu à des épidémies dont l'intensité et donc la mortalité qu'elle entraîne, essentiellement chez les personnes âgées, sont toujours imprévisibles. Cette saisonnalité de la grippe est beaucoup moins marquée dans les zones intertropicales où, cependant, les virus grippaux circulent continuellement, cette circulation contribuant certainement à leur conservation.

Tous les ans, dans les pays riches du Nord, la grippe fait parler d'elle, d'une part, au moment du lancement de la campagne de vaccination au début de l'automne et, d'autre part, lorsque le seuil épidémique est inévitablement atteint, à une date toujours imprévisible entre fin octobre et début mars. Pendant cette période, le réseau de surveillance mis en place par l'Organisation mondiale de la santé (OMS) est en alerte pour mettre en évidence les glissements antigéniques des virus afin d'actualiser le vaccin annuel, mais aussi pour saisir en temps réel l'éventuelle émergence d'un nouveau sous-type de virus A qui donnerait lieu à une pandémie, en principe après une cassure antigénique au niveau d'un virus circulant.

Après la grippe espagnole $\mathrm{A}(\mathrm{H} 1 \mathrm{~N} 1)$ de 1918 , la grippe asiatique A(H2N2) de 1958 et la grippe de Hong Kong $\mathrm{A}(\mathrm{H} 3 \mathrm{~N} 2)$ de 1968, une nouvelle pandémie était certes inéluctable, sans qu'aucune prédiction ne puisse être faite. Il fallait quand même s'y préparer. Depuis les Rencontres européennes de Berlin en 1993 du groupe d'étude et d'information sur la grippe (GEIG), l'élaboration de plans de lutte contre une pandémie fut accélérée par les États et par l'OMS.

En avril 2009, cette pandémie finit par arriver, mais sous une forme qui n'était pas exactement celle qui était attendue

P. Saliou $(\bowtie)$

20, rue Ernest-Renan, F-75015 Paris, France

e-mail : socpatex@pasteur.fr par la communauté médicoscientifique. Encore une fois, la grippe montrait son imprévisibilité !

Dans quel contexte cette pandémie est-elle survenue ?

Il est indispensable de rappeler l'épizootie de grippe aviaire (la " peste aviaire » des vétérinaires) due au virus grippal A(H5N1), en principe non transmissible à l'Homme, qui, originaire très vraisemblablement de Chine, atteignit la Corée du Sud en décembre 2003, puis, par l'intermédiaire d'oiseaux migrateurs et de la circulation non contrôlée de poussins d'élevage, se propagea de 2004 à 2007 à toute l'Asie, à l'Europe et à l'Afrique (en particulier en Côted'Ivoire, au Niger et au Nigeria). Elle mit en péril la filière aviaire, le seul moyen de contrer efficacement cette épizootie étant l'abattage des élevages de volailles. Elle a fait la une de l'actualité pendant de nombreuses semaines, d'autant plus que des cas humains grevés d'une forte létalité sont survenus chez des personnes en contact rapproché avec des volailles contaminées, probablement à cause d'une contamination massive alliée à une sensibilité individuelle qui ont permis le franchissement de la barrière d'espèce. Heureusement, aucun cas secondaire n'a jamais été confirmé.

Cependant, la crainte d'une adaptation à l'Homme de ce virus $\mathrm{A}(\mathrm{H} 5 \mathrm{~N} 1)$, par mutation qui entraînerait une pandémie catastrophique tant ce virus est virulent, accéléra la finalisation des plans de lutte et incita à développer des vaccins spécifiques adjuvés qui obtinrent leur autorisation de mise sur le marché (AMM), en Europe et aux États-Unis.

Cette épizootie ne sévit plus aujourd'hui qu'en petits foyers rapidement contrôlés en Égypte, en Indonésie et récemment au Japon, signant la permanence de la circulation $\mathrm{du}$ virus. D'ailleurs, quelques cas humains sont toujours régulièrement enregistrés. De 2003 à janvier 2011, 519 cas ont été déclarés dont 306 sont décédés, soit une létalité de $59 \%$ ! Le péril demeure entier. La pandémie $\mathrm{A}(\mathrm{H} 5 \mathrm{~N} 1)$ tant redoutée peut toujours survenir sans qu'aucune prévision ne puisse être avancée.

C'est dans cette ambiance angoissante pour les spécialistes, qu'un nouveau virus grippal que personne n'attendait surgit au Mexique en avril 2009. Vite identifié en Californie, il s'agissait cette fois non pas d'un virus issu d'une cassure antigénique, mais d'une recombinaison génétique d'un virus 
porcin $\mathrm{A}(\mathrm{H} 1 \mathrm{~N} 1)$ avec plusieurs autres virus donnant lieu à un variant $\mathrm{A}(\mathrm{H} 1 \mathrm{~N} 1) \mathrm{v}$ bien sûr pathogène pour l'Homme. En moins de neuf semaines, ce nouveau virus $A(H 1 N 1) v$ diffusa à l'ensemble de la planète. En France, le premier cas fut déclaré le $1^{\mathrm{er}}$ mai 2009. Le 11 juin, l'OMS annonça que la phase pandémique 6 , la plus élevée, était atteinte. Ce jourlà, 74 pays avaient déjà déclaré des cas. Puis, l'épidémie continua à se propager et aucun pays ne fut épargné, l'Afrique de l'Ouest étant la dernière région touchée, environ dix mois après le début de la pandémie. Car, incontestablement, cette épidémie a bien répondu à la définition d'une pandémie : diffusion mondiale très rapide, vagues épidémiques à une période inhabituelle de l'année, nouveau virus supplantant tous les autres.

Certes, cette pandémie n'a eu qu'un impact modéré sur les indicateurs de santé. Très vite, la virulence du virus s'est avérée heureusement faible entraînant un taux d'attaque modéré et surtout une létalité peu importante, touchant essentiellement des sujets à risque, les sujets jeunes et les femmes enceintes qui n'avaient jamais rencontré aucun des virus $\mathrm{A}(\mathrm{H} 1 \mathrm{~N} 1)$ circulants auparavant. Une faible homologie existant entre ces virus et le nouveau explique un certain degré d'immunité des personnes plus âgées.

L'évolution de la situation épidémiologique a amené l'OMS à déclarer la fin de la vague pandémique le 10 août 2010. En effet, au cours de l'hiver austral, d'autres virus grippaux ont prédominé dans certains pays prouvant que le virus $\mathrm{A}(\mathrm{H} 1 \mathrm{~N} 1) \mathrm{v}$, qui n'avait pas acquis de nouveaux facteurs de virulence, n'était plus capable d'assurer sa domination pandémique et de circuler de façon exclusive. Il avait adopté un comportement de virus saisonnier.

Cette pandémie a été beaucoup moins grave que l'on avait pu le craindre. Encore une fois, la grippe a montré son visage totalement imprévisible. C'est cette particularité que les experts devraient toujours mettre en avant lorsqu'ils communiquent. Le grand public est tout à fait à même de comprendre qu'incertitude scientifique n'est pas synonyme d'incompétence.
Malheureusement, tant au niveau de l'OMS qu'à celui des autorités sanitaires nationales, en France en particulier, la communication a été très alarmiste dès le début. Puis, elle n'a pas su s'adapter à la réalité de l'évolution de la pandémie, qui, rapidement s'est avérée non catastrophique. Elle a alors été mal perçue dans l'opinion et même auprès d'une partie du corps médical, d'autant plus que diverses théories du complot, sans fondement, non contrôlées et non suffisamment démenties ont circulé sur le net.

Certes, au début de la pandémie, tous les moyens ont été mis en œuvre pour y faire face. Les plans pandémiques étaient prêts. Rapidement, la souche virale responsable a été identifiée et distribuée aux industriels qui ont fabriqué un vaccin répondant parfaitement aux normes de l'AMM. Indéniablement, ce vaccin pandémique était efficace et non dangereux. Des évaluations indépendantes financées par le Centre européen de prévention et de lutte contre les maladies (ECDC) ont montré que cette efficacité vaccinale jugée sur l'apparition de grippe confirmée se situait entre 75 et $95 \%$, après une seule injection et non après deux doses, comme il est nécessaire avec le vaccin $\mathrm{A}(\mathrm{H} 5 \mathrm{~N} 1) \ldots$ et comme il avait été annoncé avant le résultat des études !

L'évolution de la pandémie justifiait totalement la vaccination des personnes à risques, des jeunes et des femmes enceintes. Mais celle de toute la population était beaucoup plus discutable, et d'ailleurs le public n'a pas suivi, notamment en France, en raison d'erreurs dans la conception et dans l'évolution de l'organisation de la campagne.

Aujourd'hui, il est absolument nécessaire de retrouver la confiance de ce public sans l'inquiéter outre mesure.

Oui, la politique vaccinale annuelle est totalement justifiée. Oui, une nouvelle pandémie surviendra un jour, la crainte d'une éventuelle pandémie $\mathrm{A}(\mathrm{H} 5 \mathrm{~N} 1)$ continuant à planer.

Plus que jamais, il est nécessaire de communiquer vers le grand public en insistant sur le fait que l'épidémiologie de la grippe est totalement imprévisible en l'état actuel des connaissances. 